\title{
Ischaemic Preconditioning: The Rationale and Evidence-Based Outcomes
}

\author{
George Hamilton
}

\subsection{Introduction}

Reperfusion injury is a process well recognised and understood by vascular surgeons where return of arterialised blood flow to a previously ischaemic organ or tissue often results in a complex pathophysiological cascade ending in potentially irreversible cellular damage. The sequelae of this process are frequently seen in vascular surgery after reperfusion of a previously ischaemic lower limb. The resulting profoundly acute inflammatory syndrome gives rise to raised compartmental pressure within the muscles of the lower limb requiring fasciotomy. Reperfusion injury however can develop in several other surgical scenarios including coronary artery bypass grafting and other cardiac interventions, organ transplantation and major vascular surgery, in particular aortic aneurysm repair and carotid endarterectomy. Obviously in these scenarios, fasciotomy is not an option, and since the 1980s, there has been research into avoiding or at least mitigating reperfusion injury.

\footnotetext{
G. Hamilton $(\bowtie)$

Royal Free London NHS Foundation Trust, London, UK

Great Ormond Street Hospital NHS Foundation Trust, London, UK

Medical School, University College London, London, UK

e-mail: g.hamilton@ucl.ac.uk
}

The initial focus was on treating reperfusion injury in coronary artery bypass grafting for myocardial ischaemia. This involved applying limited periods of ischaemia alternating with reperfusion before completion of a coronary artery bypass graft. This technique, known as ischaemic postconditioning, has been assessed in several clinical trials which have confirmed that infarct size can be reduced with this methodology [1]. A major drawback of this technique however is that it is highly invasive.

Following this discovery the possibility of preconditioning before the ischaemiareperfusion insult to a target organ was explored. Remote ischaemic preconditioning was first shown to have a beneficial effect on other organs and tissues in the heart [2]. This finding generated a great deal of interest and research into the possible effects of remote preconditioning particularly as the methodology was inherently safe and non-invasive. There have been various protocols, but most commonly the remote preconditioning process involves inflation of a tourniquet or blood pressure cuff above systolic arterial pressure of the upper limb with alternating periods most commonly of $5 \mathrm{~min}$ of ischaemia followed by $5 \mathrm{~min}$ reperfusion. There have been many studies, both experimentally in animals and clinically with differing preconditioning protocols, indicating that the optimal preconditioning schedules may be different for the individual target organs. 


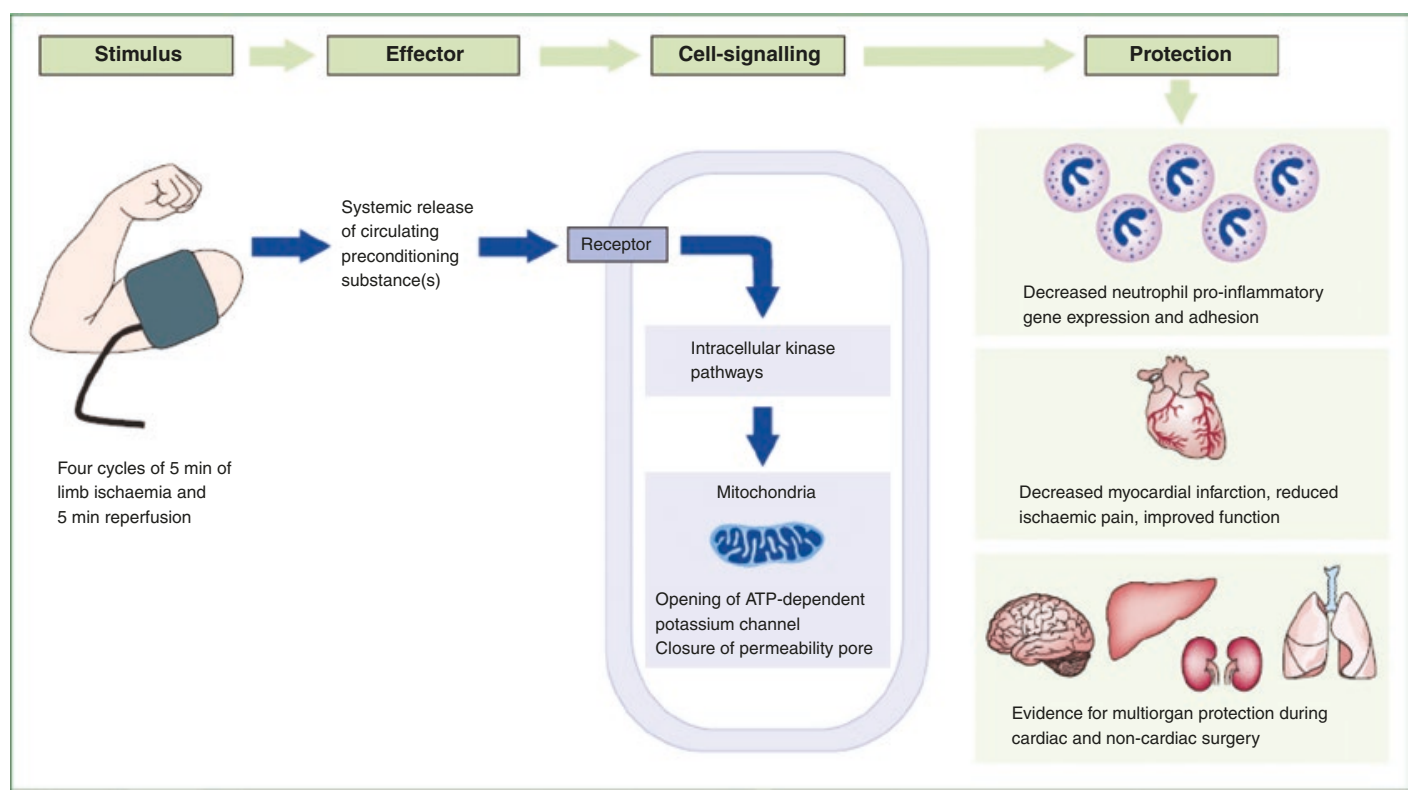

Fig. 2.1 Remote ischaemic preconditioning stimulates release of 'humoral' moieties into the circulation to modulate the potentially fatal effects of organs or tissues under prolonged ischaemia. Taken from [4]

\subsection{Current Understanding of the Potential Protective Effects of Preconditioning}

The pathophysiology of reperfusion injury is complex and will not be described in detail in this chapter. The central pathophysiological process is postulated to be an increase in mitochondrial permeability transition pore opening. This results in profound impairment of mitochondrial activity, ATP production and cell death. The end result of ischaemic preconditioning signalling is inhibition of this effect [3]. The protective effect of remote preconditioning implies that the molecules and mechanisms activated within the skeletal muscle of the preconditioned arm are transferred systemically to provide a similar protective effect across the body and its various organs. Two waves of effects have been identified, the first early preconditioning known as the early window of protection and the second happening over the days or weeks following known as the second window of protection.

Three major pathways have been confirmed to be involved in the early wave of protection, namely, the humeral route with release of active molecules, the neurogenic pathway with direct effects on nerve signalling on end organs and the immunological route by alteration of immune cells (Fig. 2.1). As a result of activation of the humeral and neurogenic pathways, kinase cascades are induced which will mitigate open mitochondrial permeability transition pores; the immune pathway probably works by modulation of gene and receptor expression on immune cells modulating the inflammatory response. The second window of protection also implicates release of iNOS and COX-2 [3].

\subsection{Methods of Preconditioning}

There are various methods described in clinical preconditioning. In cardiothoracic and vascular surgery, more invasive preconditioning techniques are possible, for example, temporary occlusion of a coronary artery in coronary artery bypass grafting or temporary occlusion of the iliac artery or other intra-abdominal arteries during open abdominal vascular surgery. With specific regard to the evidence base for vascular surgery, the immediate methodologies mostly 
involve clamping of one of the iliac arteries once the peritoneal cavity is opened and before the reconstructive procedure for either aneurysmal or occlusive disease takes place. A typical protocol would be clamping of the left common iliac artery for a period of 5 min with removal of the clamp and reperfusion for a further period of $5 \mathrm{~min}$, and this cycle is repeated 3-5 times. An alternative is clamping of the supra-coeliac aorta with a similar schedule_obviously this requires more dissection and presents greater haemodynamic challenge to the vascular patient and the associated pathologies.

The preferred methodology involves inducing ischaemia-reperfusion cycles on the skeletal muscle most commonly of the arm or less commonly of the leg. This is achieved by placement of a tourniquet with inflation above systolic pressure. Typical schedules involve 5 min periods of occlusion followed by 5 min of reperfusion with repetition of the cycle between three and five times. In common to all of these remote preconditioning methodologies, this is performed before the definitive procedure takes place.

\subsection{The Evidence for Ischaemic Preconditioning}

\subsubsection{Animal Studies}

There is a very extensive literature on ischaemic preconditioning in animal models which are important in understanding the pathophysiology. Furthermore, the positive evidence from these animal studies is much more definitive and conclusive than that found in clinical studies. With specific regard to the effect of ischaemiareperfusion on organs, the intestine is found to be more sensitive to the adverse effects than other internal organs [5]. Animal studies have focused on clarifying the various mechanisms involved in ischaemia reperfusion particularly focusing on neutrophilic activation of inflammatory mediators and cell apoptosis. Typical of these studies is a recent report from Gian Xi' an from China which found that ischaemic preconditioning by occlusion of the superior mesenteric artery in rats ame- liorated intestinal injury. This was by attenuation of the neutrophil-endothelial adhesion cascade by reduction of ICAM-1 and VCAM-1 expression and also of the TNF-alpha-induced NF- $\mathrm{KB}$ signalling pathway [6].

Review of the experimental in vivo data shows an almost universal benefit for ischaemic preconditioning in all organs studied. These positive results continue to be a major driver for ongoing research to further unravel and understand the mechanisms involved.

\subsubsection{The Clinical Evidence for Ischaemic Preconditioning}

There is a considerable body of evidence based on clinical trials and series reporting looking primarily at its effects on the heart, brain and kidney as individual organs. There is also a respectable body of evidence with regard to its effects in vascular surgery, primarily focused on abdominal aortic aneurysm repair.

\subsection{Cardiac Surgery}

In common with studies in other organs, the early reports were based on measurement of surrogate markers. Since 2010 the focus is more on clinical outcomes. These primary end points were death, acute kidney injury or renal failure, stroke and non-fatal myocardial infarction. There have been several meta-analyses with the most recent reported in 2016 analysing a total of 5652 patients in 27 trials. In this meta-analysis, remote ischaemic preconditioning was found to reduce the risk of myocardial infarction from $12.6 \%$ to $10.2 \%$ (OR $0.72,95 \%$ CI $0.52-1.00$ ) and acute renal failure from $22.9 \%$ to $20.6 \%$ (OR 0.73 , 95\% CI 0.53-1.00). In addition to a reduction of composite all-cause mortality, myocardial infarction, stroke or acute renal failure from $43.2 \%$ to $39.2 \%$ (OR 0.60, 95\% CI 0.39-0.90), there was also a significantly shorter stay in intensive care as well as total hospital stay. No differences were found however in mortality (OR 1.10, 95\% CI 0.81-1.51) [7]. 


\subsection{The Kidney}

A recent review for the Cochrane database on "Ischaemic preconditioning for the reduction of renal ischaemia reperfusion injury" analyses all the up-to-date data. This exhaustive analysis looked at outcomes both primary and secondary with sub-analysis for the method of remote ischaemic preconditioning used and the type of surgical intervention (open abdominal vascular surgery, cardiothoracic surgery and transplantation) [3]. The outcomes identified were universally negative in the 28 studies identified. There was no protective effect for primary or secondary endpoints. In terms of the method for remote ischaemic preconditioning used, adverse effects were found in one study after invasive vascular clamping, but no adverse effects were found with cuff inflation to the arm or leg. A possible significant benefit was found in this review with a subgroup of patients who underwent invasive clamping of the arteries prior to the procedure which seemed to be more effective compared to the non-invasive cuff inflation. The review urges care in interpretation of this however since this finding was based on only three studies with one of them having a high degree of heterogeneity. This review came to the conclusion that based on up-to-date data, the routine use of remote ischaemic preconditioning in major surgery at the present time cannot be justified. The authors conclude however that further randomised controlled trials should take place with the recommendation that these should focus on surgery involving significant kidney ischaemia-reperfusion injury, in particular open abdominal aortic or kidney transplant surgery.

\subsection{Vascular Surgery}

There have been several clinical trials of remote ischaemic preconditioning in vascular surgery, most of which are randomised and blinded. Composite primary endpoints were used in the majority, namely, of mortality, myocardial infarction, stroke and renal and respiratory failure, in addition to measurement of troponin-1 values.
The most recent studies in vascular surgery have been on an "all comers" basis including various vascular procedures such as open and endovascular abdominal aortic aneurysm repair, lower limb bypass surgery and carotid endarterectomy. A possibly important consideration in interpretation of the outcomes is the heterogeneity in the data with regard to general and anaesthetic protocols. In particular the use of propofol may have an inhibitory effect on the possible cardioprotective properties of remote ischaemic preconditioning [8].

Table 2.1 Lists of the trials specific to vascular surgery

Review of these trials universally shows no effect on myocardial injury, renal injury or clinical outcomes based on moderate to high level data with 7 out of the 11 trials being blinded prospective randomised comparisons [9-19].

There are a total of four meta-analyses of evidence for remote ischaemic preconditioning in vascular surgery [20] (Table 2.2).

The results show no benefit for either clinical outcomes or biomarkers, from remote ischaemic preconditioning for patients undergoing vascular surgery. This is true for patients having abdominal aortic aneurysm repair, carotid endarterectomy or peripheral revascularisation [21-24].

\subsection{Summary}

Virtually all of the available clinical evidence confirms that there is no clinically relevant benefit from remote ischaemic preconditioning for patients undergoing vascular surgery. This lack of benefit includes all of the end organs studied, namely, the heart, kidney, lungs and brain (the data for the lung and brain have not been included in this chapter) and specifically regarding any beneficial effect on the bowel or the end organs of the mesenteric circulation. There is an abundance of data however from animal studies showing significant beneficial effects of remote ischaemic preconditioning. From the animal data, we can conclude that there is a clear potential significant benefit but that this has not translated to the present clinical scenario with current protocols. 
There are several possible explanatory rea- in patients with multiple comorbidities. sons why this translation cannot be demonstrated. Furthermore, hyperlipidaemia and diabetes may The first major consideration is that the in vivo have an attenuating effect on ischaemic precondistudies were all performed in healthy younger tioning, both important comorbidities frequently animals, while obviously the human studies were present in vascular patients $[25,26]$.

Table 2.1 Trials specific to vascular surgery

\begin{tabular}{|c|c|c|c|c|c|}
\hline Author & Numbers & Stimulus & Blinding & Propofol & Outcomes \\
\hline Ali et al. [9] & 82 AAA & Iliac clamping & Yes & Yes & $\begin{array}{l}\text { Reduced } \\
\text { biomarkers }\end{array}$ \\
\hline Walsh et al. [10] & 40 AAA & Iliac clamping & Yes & Yes & No difference \\
\hline Murphy et al. [11] & 62 AAA & Arm cuff & Yes & Yes & No difference \\
\hline Li et al. [12] & 62 AAA & Arm cuff & Yes & Yes & $\begin{array}{l}\text { Reduced } \\
\text { inflammatory } \\
\text { response lung and } \\
\text { intestines }\end{array}$ \\
\hline Walsh et al. [13] & 70 CEA & Leg cuff & No & Yes & No difference \\
\hline Walsh et al. [14] & 40 EVAR & Leg cuff & No & Yes & No difference \\
\hline Healey et al. [15] & $\begin{array}{l}198 \text { AAA open and } \\
\text { EVAR, CEA, limb } \\
\text { revascularisation }\end{array}$ & Arm cuff & No & $\begin{array}{l}\text { Not } \\
\text { known }\end{array}$ & No difference \\
\hline Mouton et al. [16] & $\begin{array}{l}69 \text { AAA open or } \\
\text { EVAR }\end{array}$ & Arm cuff & $\begin{array}{l}\text { Surgeons } \\
\text { blinded }\end{array}$ & $\begin{array}{l}\text { Not } \\
\text { known }\end{array}$ & No difference \\
\hline Garcia et al. [17] & $\begin{array}{l}201 \text { AAA open and } \\
\text { EVAR, CEA, limb } \\
\text { revascularisation }\end{array}$ & $\begin{array}{l}\text { Arm cuff } 12-24 \mathrm{~h} \\
\text { before surgery }\end{array}$ & Yes & $\begin{array}{l}\text { Not } \\
\text { known }\end{array}$ & No difference \\
\hline Thomas et al. [18] & $\begin{array}{l}85 \text { AAA open and } \\
\text { EVAR, limb } \\
\text { revascularisation }\end{array}$ & $\begin{array}{l}\text { Arm cuff } 24 \mathrm{~h} \text { before } \\
\text { and then following } \\
\text { anaesthesia }\end{array}$ & Yes & Yes & No difference \\
\hline Coverdale et al. [19] & $\begin{array}{l}67 \text { AAA, CEA, limb } \\
\text { revascularisation, } \\
\text { other }\end{array}$ & $\begin{array}{l}\text { Arm cuff during GA } \\
\text { before transfer to OR }\end{array}$ & Yes & Yes & No difference \\
\hline
\end{tabular}

$A A A$ abdominal aortic aneurysm, $E V A R$ endovascular aortic aneurysm repair, $C E A$ carotid endarterectomy

Table 2.2 Meta-analyses of evidence for remote ischaemic preconditioning in vascular surgery

\begin{tabular}{|c|c|c|c|c|c|c|}
\hline Author & Year & Trials included & $\begin{array}{l}\text { Number of } \\
\text { studies } \\
\text { (participants }^{a} \text { ) }\end{array}$ & $\begin{array}{l}\text { Type of } \\
\text { study }\end{array}$ & $\begin{array}{l}\text { Major findings and (OR, } \\
\text { SMD, and } 95 \% \mathrm{CI})\end{array}$ & $\begin{array}{l}\text { Risk of bias } \\
\text { from included } \\
\text { studies }\end{array}$ \\
\hline \multirow[t]{4}{*}{$\begin{array}{l}\text { Desai et al. } \\
{[21]}\end{array}$} & \multirow[t]{4}{*}{2011} & \multirow[t]{4}{*}{$\begin{array}{l}\text { Vascular and } \\
\text { endovascular }\end{array}$} & \multirow[t]{4}{*}{$\begin{array}{l}4 \text { studies }(232 \\
[115: 117])\end{array}$} & \multirow[t]{4}{*}{ RCT } & $\begin{array}{l}\text { RIPC improved: } \\
\text { Myocardial infarction }{ }^{\mathrm{b}} \text { : } \\
(\text { OR } 0.31[1.10-0.90] \\
p=0.03)\end{array}$ & \multirow[t]{4}{*}{ Low } \\
\hline & & & & & $\begin{array}{l}\text { No improvement: } \\
\text { Mortality: (OR } 1.70 \\
[0.91-5.92] p=0.39)\end{array}$ & \\
\hline & & & & & $\begin{array}{l}\text { Renal failure: }(\mathrm{OR} 0.74 \\
[0.35-1.54] P=0.42)\end{array}$ & \\
\hline & & & & & $\begin{array}{l}\text { Hospital stay: } \\
(\mathrm{SMD}-0.12[-2.38- \\
2.13] p=0.91)\end{array}$ & \\
\hline
\end{tabular}


Table 2.2 (continued)

\begin{tabular}{|c|c|c|c|c|c|c|}
\hline Author & Year & Trials included & $\begin{array}{l}\text { Number of } \\
\text { studies } \\
\text { (participants }^{\mathrm{a}} \text { ) }\end{array}$ & $\begin{array}{l}\text { Type of } \\
\text { study }\end{array}$ & $\begin{array}{l}\text { Major findings and (OR, } \\
\text { SMD, and } 95 \% \mathrm{CI})\end{array}$ & $\begin{array}{l}\text { Risk of bias } \\
\text { from included } \\
\text { studies }\end{array}$ \\
\hline $\begin{array}{l}\text { Brevoord } \\
{[22]}\end{array}$ & 2012 & $\begin{array}{l}\text { Vascular, } \\
\text { endovascular, open } \\
\text { cardiac surgery, } \\
\text { percutaneous cardiac } \\
\text { intervention }\end{array}$ & $\begin{array}{l}23 \text { studies } \\
(1878 \\
[954: 924])\end{array}$ & RCT & 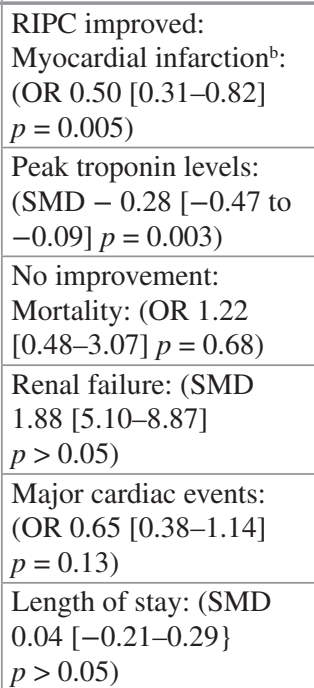 & Moderate \\
\hline $\begin{array}{l}\text { Li et al. } \\
{[23]}\end{array}$ & 2013 & $\begin{array}{l}\text { Vascular, } \\
\text { endovascular, open } \\
\text { cardiac surgery, } \\
\text { percutaneous cardiac } \\
\text { intervention }\end{array}$ & $\begin{array}{l}10 \text { studies }(924 \\
[464: 460])\end{array}$ & RCT & $\begin{array}{l}\text { No improvement: } \\
\text { Mortality: (OR } 1.21 \\
[0.49-2.97] p=0.68) \\
\text { Renal failure: }(\mathrm{OR} 0.73 \\
[0.50-0.64] p=0.18) \\
\text { Length of stay: }(\mathrm{SMD} \\
0.07[-0.50-0.64\} \\
p=0.81)\end{array}$ & Moderate \\
\hline $\begin{array}{l}\text { Takagi and } \\
\text { Umemoto } \\
{[24]}\end{array}$ & 2011 & $\begin{array}{l}\text { Vascular and open } \\
\text { cardiac }\end{array}$ & $\begin{array}{l}9 \text { studies (488 } \\
\text { unclear) }\end{array}$ & RCT & $\begin{array}{l}\text { RIPC improved: Peak } \\
\text { troponin levels: }(\mathrm{SMD} \\
-0.74[-0.97 \text { to }-0.52] \\
p<0.00001)\end{array}$ & Moderate \\
\hline
\end{tabular}

$R C T$ randomised controlled trial, $R I P C$ remote ischaemic preconditioning, $S M D$ standardised mean difference

Ref. [20] (Twine CP, Ferguson S, Boyle JR. Review: benefits of remote ischaemic preconditioning in vascular surgery. Eur J Vasc Endovasc Surg. 2014; 48(2):215-9)

aPreconditioned-non-preconditioned.

${ }^{\mathrm{b}}$ Defined predominantly by troponin levels

As previously discussed, the anaesthetic protocols were heterogeneous throughout these clinical trials and importantly with particular regard to the attenuating effect of propofol. Future clinical trials of remote ischaemic preconditioning in vascular surgery must include clear anaesthetic protocols designed to either exclude or assess the effects of this anaesthetic agent.

The method of remote ischaemic preconditioning has also been variable, with a confounding mixture of the predominantly upper limb and then lower limb together with less commonly intraoperative preconditioning by clamping of 
major vessels. Of interest there is one trial of remote ischaemic preconditioning in vascular surgery where there was an improvement in biomarkers with cross clamping of the iliac artery but which also caused four episodes of significant damage to the iliac artery [9].

This raises the hypothesis that the extent or mass of rendered tissue ischaemia may be of importance. Compared to cuffed ischaemia of an upper or lower limb, clamping of a common iliac artery will result in activation of the ischaemic reperfusion cascade throughout a much greater mass of tissue. Various authors have further postulated that cuff-based preconditioning may have an effect which is overwhelmed by the attenuation from all of the clinical factors described above. However without exception, all recent authors conclude that there should be further better defined trials of remote ischaemic preconditioning given the overwhelmingly positive evidence in the animal trials and the safety of cuffed-based ischaemic protocols. In the meantime however there is no basis to recommend the routine use of remote ischaemic preconditioning in vascular surgery outside of clinical trials.

\section{References}

1. Ovize M, Mewton N. Interventional cardiology: ischaemic POSTconditioning-a long harvest for a little corn. Nat Rev Cardiol. 2014;11:8-10.

2. Przyklenk K, Bauer B, Ovize M, Kloner RA, Whittaker P. Regional ischaemic "preconditioning" protects remote virgin myocardium from subsequent sustained coronary occlusion. Circulation. 1993;87:893-9.

3. Menting TP, Wever KE, Ozdemir-van Brunschot DM, Van der Vliet DJ, Rovers MM, Warle MC. Ischaemic preconditioning for the reduction of renal ischaemia reperfusion injury. Cochrane Database Syst Rev. 2017;3:CD010777. https://doi. org/10.1002/14651858.CD010777.pub2.

4. Kharbanda RK, Nielsen TT, Redington AN. Translation of remote ischaemic preconditioning into clinical practice. Lancet. 2009;374:1557-65.

5. Xing D, Zhang R, Li S, Huang P, Luo C, Hei Z, Xia Z, Gan X. Pivotal role of mast cell carboxypeptidase $\mathrm{A}$ in mediating protection against small intestinal ischemia-reperfusion injury in rats after ischemic preconditioning. J Surg Res. 2014;192:177-86.
6. Gi YY, Wang ZD, Wang SF, Wang WT, Yang ZA, Zhou XR, Lei NN, Yue WN. Ischemic preconditioning ameliorates intestinal injury induced by ischemia-reperfusion in rats. World J Gastro Enterol. 2015;21:8081-8.

7. Sardar P, Chatterjee S, Kundu A, et al. Remote ischemic preconditioning in patients undergoing cardiovascular surgery: evidence from a metanalysis of randomised controlled trial. Int $\mathrm{J}$ Cardiol. 2016;221:34-41.

8. Kottenberg E, Thielmann M, Bergmann L, et al. Protection by remote ischemic preconditioning during coronary artery bypass graft surgery with isoflurane but not propofol-a clinical trial. Acta Anaesthesiol Scand. 2012;56(1):30-8.

9. Ali ZA, Callaghan CJ, Lim E, et al. Remote ischemic preconditioning reduces myocardial and renal injury after elective abdominal aortic aneurysm repair: a randomized controlled trial. Circulation. 2007;116(11 suppl):I98-I105.

10. Walsh SR, Sadat U, Boyle JR, et al. Remote ischemic preconditioning for renal protection during elective open infrarenal abdominal aortic aneurysm repair: randomized controlled trial. Vasc Endovasc Surg. 2010;44(5):334-40.

11. Murphy N, Vijayan A, Frohlich S, et al. Remote ischemic preconditioning does not affect the incidence of acute kidney injury after elective abdominal aortic aneurysm repair. J Cardiothorac Vasc Anesth. 2014;28(5):1285-92.

12. Li C, Li YS, Xu M, et al. Limb remote ischemic preconditioning for intestinal and pulmonary protection during elective open infrarenal abdominal aortic aneurysm repair: a randomized controlled trial. Anesthesiology. 2013;118(4):842-52.

13. Walsh SR, Nouraei SA, Tang TY, Sadat U, Carpenter $\mathrm{RH}$, Gaunt ME. Remote ischemic preconditioning for cerebral and cardiac protection during carotid endarterectomy: results from a pilot randomized clinical trial. Vasc Endovasc Surg. 2010;44(6):434-9.

14. Walsh SR, Boyle JR, Tang TY, et al. Remote ischemic preconditioning for renal and cardiac protection during endovascular aneurysm repair: a randomized controlled trial. J Endovasc Ther. 2009;16(6):680-9.

15. Healy DA, Boyle E, McCartan D, et al. A multi center pilot randomized controlled trial of remote ischemic preconditioning in major vascular surgery. Vasc Endovasc Surg. 2015;49(8):220-7.

16. Mouton R, Pollock J, Soar J, Mitchell DC, Rogers CA. Remote ischaemic preconditioning versus sham procedure for abdominal aortic aneurysm repair: an external feasibility randomized controlled trial. Trials. 2015;16:377.

17. Garcia S, Rector TS, Zakharova M, et al. Cardiac remote ischemic preconditioning prior to elective vascular surgery (CRIPES): a prospective, randomized, sham-controlled phase II clinical trial. J Am Heart Assoc. 2016;5(10):e003916.

18. Thomas KN, Cotter JD, Williams MJ, van Rij AM. Repeated episodes of remote ischemic precondi- 
tioning for the prevention of myocardial injury in vascular surgery. Vasc Endovasc Surg. 2016;50(3):140-6.

19. Coverdale NS, Hamilton A, Petsikas D, McClure RS, Malik P, Milne B, Saha T, Zelt D, Brown P, Payne DM. Remote ischaemic preconditioning in high risk cardiovascular surgery patients: a randomised controlled trial. Semin Thorac Cardiovasc Surg. 2017;30(1):26-33.

20. Twine CP, Ferguson S, Boyle JR. Review: benefits of remote ischaemic preconditioning in vascular surgery. Eur J Vasc Endovasc Surg. 2014;48(2):215-9. https:// doi.org/10.1016/j.ejvs.2014.05.008.

21. Desai M, Gurusamy KS, Ghanbari H, Hamilton G, Seifalian AM. Remote ischaemic preconditioning versus no remote ischaemic preconditioning for vascular and endovascular surgical procedures. Cochrane Database Syst Rev. 2011;12:CD008472.

22. Brevoord D, Kranke P, Kuijpers M, Weber N, Hollmann M, Preckel B. Remote ischemic conditioning to protect against ischemia-reperfusion injury: a systematic review and metanalysis. PLoS One. 2012;7:e42179.

23. Li L, Li G, Yu C, Li Y. The role of remote ischemic preconditioning on postoperative kidney injury in patients undergoing cardiac and vascular interventions: a meta-analysis. J Cardiothorac Surg. 2013;8:43.

24. Takagi H, Umemoto T. Remote ischemic preconditioning for cardiovascular surgery: an updated metaanalysis of randomized trials. Vasc Endovasc Surg. 2011;45:511e3.

25. Ungi I, Ungi T, Ruzsa Z, et al. Hypercholesterolaemia attenuates the anti-ischaemic effect of preconditioning during coronary angioplasty. Chest. 2005;128:1623-8.

26. Ishihara M, Inoue I, Kawagoe T, et al. Diabetes mellitus prevents ischaemic preconditioning in patients with a first acute anterior wall myocardial infarction. J Am Coll Cardiol. 2001;38:1007-11. 